\title{
RESOLUTION OF PARENTAGE IN DOGS BY EXAMINATION OF MICROSATELLITES AFTER DEATH OF PUTATIVE SIRE: CASE REPORT
}

\author{
Z. PÁdÁR ${ }^{1}$, B. EGYed ${ }^{1}$, K. KONTADAKIS ${ }^{2}$, L. ZÖLDÁG ${ }^{2 *}$ and S. FeKETE ${ }^{2}$ \\ ${ }^{1}$ DNA Laboratory, Institute for Forensic Sciences, P.O. Box 314/4, H-1903 Budapest, \\ Hungary; ${ }^{2}$ Department of Animal Breeding, Nutrition and Laboratory Animal Science, \\ Faculty of Veterinary Science, Szent István University, Budapest, Hungary
}

(Received November 7, 2000; accepted February 8, 2001)

\begin{abstract}
A case of disputed paternity in dogs is reported. DNA examinations were carried out from hair samples of the individuals several months after the death of the putative sire. Ten short tandem repeat (STR) loci were analysed by fluorescence-labelled multiplex PCR using ABI PRISM 310 Genetic Analyser. Based on the results the candidate sire was included in the pedigree records as the biological sire. In spite of the genetic homogeneity of pedigree dogs due to inbreeding, canine microsatellites can provide an adequate basis for assigning paternity in pure breeds.
\end{abstract}

Key words: Dog, microsatellites, parentage control

Currently there is a great interest in ensuring correctly reported pedigrees world-wide (Vriesendorp et al., 1974; Zajc et al., 1994). According to commercial and breeding considerations, the accurate determination of relatedness in companion animals has become increasingly important. The chance of champion heritage or genetic health coupled with individual identification are useful information for the breeders. The demand for an efficient routine system as an integral part of the registration process is manifested in Hungary, too. The establishment of short tandem repeat (STR) examination employing commercialised multiplex PCR methodology can be an adaptable solution (Francisco et al., 1996; Zajc et al., 1997).

The ten microsatellite markers applied (PEZ1, FHC2054, FHC2010, PEZ5, PEZ20, PEZ12, PEZ3, PEZ6, PEZ8 and FHC2079 loci) appear to be efficient for resolving disputed paternity cases. In the case reported here this procedure is executable and has less dependence on time and on the direct presence of the individual animal. The goal of this work is to demonstrate that having biological samples preserved in a bank or a determined genetic profile in an accept-

${ }^{*}$ Corresponding author: Department of Animal Breeding, Nutrition and Laboratory Animal Science, Faculty of Veterinary Science, Szent István University, H-1400 Budapest, P.O. Box 2, Hungary; E-mail: lzoldag@univet.hu; Fax: +36 (1) 478-4128 
able reference DNA database can be powerful tools in such cases, even without access to the living individual. Performance of the analysis on preserved or conserved sources of DNA is relatively flexible in time, and the parentage of an individual can be determined with high probability. The difficulties due to closely related dogs (sibling or son of intended sire) strongly suggest that exact population studies of local populations increase the accuracy of allele frequencies and statistical evaluation (Fredholm and Winters, 1996).

\section{Case report}

Two English bulldog puppies were born in a Hungarian kennel after the death of their alleged sire. Correct identification of the sire was especially important for the breeders for the benefit of breeding. The owner had conserved a few hairs from the coat of the dead dog, which were usable DNA sources for genetic comparison with the litter. Based on the analysis of hairs the alleged sire was included in the pedigree records as the biological sire months after his death.

\section{Materials and methods}

A few plucked hairs of the bitch and puppies were collected. Preserved hair samples of the deceased sire were used for comparison. The 5-8 $\mathrm{mm}$ long root ends of hairs were cut and rinsed in sterile deionised water. All of the hairroots as a potential DNA source were extracted as described previously (FBI Laboratory, 1994; Shutler et al., 1999). The highly concentrated DNA (approx. $10 \mathrm{ng}$ ) was co-amplified in PCR decaplex using reagents provided in the StockMark Kit Canine I Ver.3 (PE AgGen, Inc. Foster City, CA) according to the manufacturer's instructions. Electrophoresis and data collection were performed on ABI PRISM 310 Genetic Analyser applying fluorescent ladder CXR 60-400 (Promega Corp.) as internal size standard.

\section{Results and discussion}

The effect of seasonal shedding of coat resulted in great differences in the total number of cells in the hair bulbs. Due to the sampling of hairs and ultraconcentration of extracted DNA the genetic profile from all of the hair samples was available for determination. Computerised measurement of allele size was done by applying CXR60-400. The achieved sizing precision of $\leq 0.27$ nucleotide (nt) standard deviation allows a $\pm 0.5 \mathrm{nt}$ allele size window to be set for genotyping (Table 1). 
Although somatic mutations are believed to occur with higher probability in the integument than in other tissues, considering the mixed feature (amplified DNA obtained from a few hairs of each individual) of extracted DNA, the clear profiles found and the equilibrium of amplified heterozygote alleles do not support this assumption. The genetic profiles of the litter do not include alleles from an unidentified individual. Therefore, the candidate dog was included in the pedigree records as the biological sire (Figs 1 and 2).

Table 1

Detected size of amplified fragments in an English bulldog kennel

\begin{tabular}{lcccccc}
\hline \multicolumn{1}{c}{ Locus } & Dam & Sire & Puppy $_{1}$ & Puppy $_{2}$ & Mean $_{\text {(nt) }}$ & SD $_{\text {(nt) }}$ \\
\hline PEZ1 & 111.85 & 111.61 & 11.62 & 111.68 & 111.69 & 0.11 \\
PEZ1 & & 115.91 & 115.92 & 115.89 & 115.91 & 0.02 \\
FHC2054 & & 146.38 & & 146.41 & 146.40 & 0.02 \\
FHC2054 & 154.66 & & & & & \\
FHC2054 & 166.73 & 166.69 & 166.61 & 166.60 & 166.66 & 0.06 \\
FHC2010 & & 224.38 & 224.25 & 224.38 & 224.34 & 0.08 \\
FHC2010PE & 228.85 & & 228.38 & 228.84 & 228.69 & 0.27 \\
PEZ5 & 98.42 & 98.31 & 98.54 & 98.54 & 98.45 & 0.11 \\
PEZ5 & 102.63 & & & & & \\
PEZ20 & 171.70 & 171.27 & 171.58 & 171.69 & 171.56 & 0.20 \\
PEZ12 & 266.55 & 266.18 & 266.57 & 266.44 & 266.44 & 0.18 \\
PEZ3 & 123.82 & & 123.92 & & 123.87 & 0.07 \\
PEZ3 & 126.95 & 126.95 & 126.92 & 127.05 & 126.97 & 0.06 \\
PEZ6 & 180.00 & 179.76 & 179.88 & 180.00 & 179.91 & 0.11 \\
PEZ6 & & 183.70 & 183.69 & & 183.70 & 0.01 \\
PEZ8 & 225.0 & & & & & \\
PEZ8 & & 228.87 & & 228.84 & 228.86 & 0.02 \\
PEZ8 & 23.09 & 232.99 & 233.03 & 232.94 & 233.01 & 0.06 \\
FHC2079 & 266.55 & 266.18 & 266.57 & 266.44 & 266.44 & 0.18 \\
FHC2079 & 270.39 & 270.39 & & 270.40 & 270.39 & 0.01 \\
\hline
\end{tabular}

The sire can be identified using the allele designation obtained by measuring standard deviations (SD). $\mathrm{nt}=$ nucleotide

The genetic homogeneity of pedigree dogs due to inbreeding could cause a higher level of homozygosity at specific loci (Fig. 3). The exact statistical evaluation of paternity probability requires further population studies of Hungarian pure-bred populations and an expanded analysis of mutation rate, which are currently in progress. 


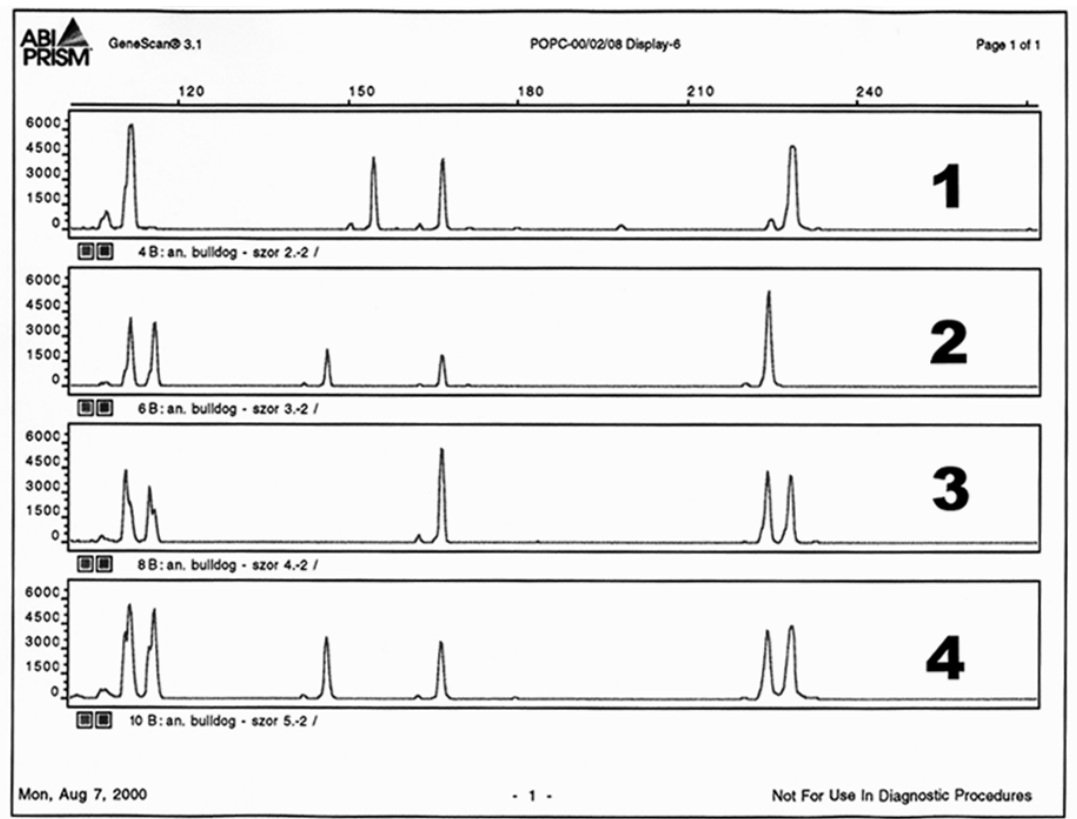

Fig. 1. Result of examination (left to right) of PEZ1, FHC2054 and FHC2010 loci $1=$ dam, $2=$ sire, $3=$ puppy $_{1}, 4=$ puppy $_{2}$

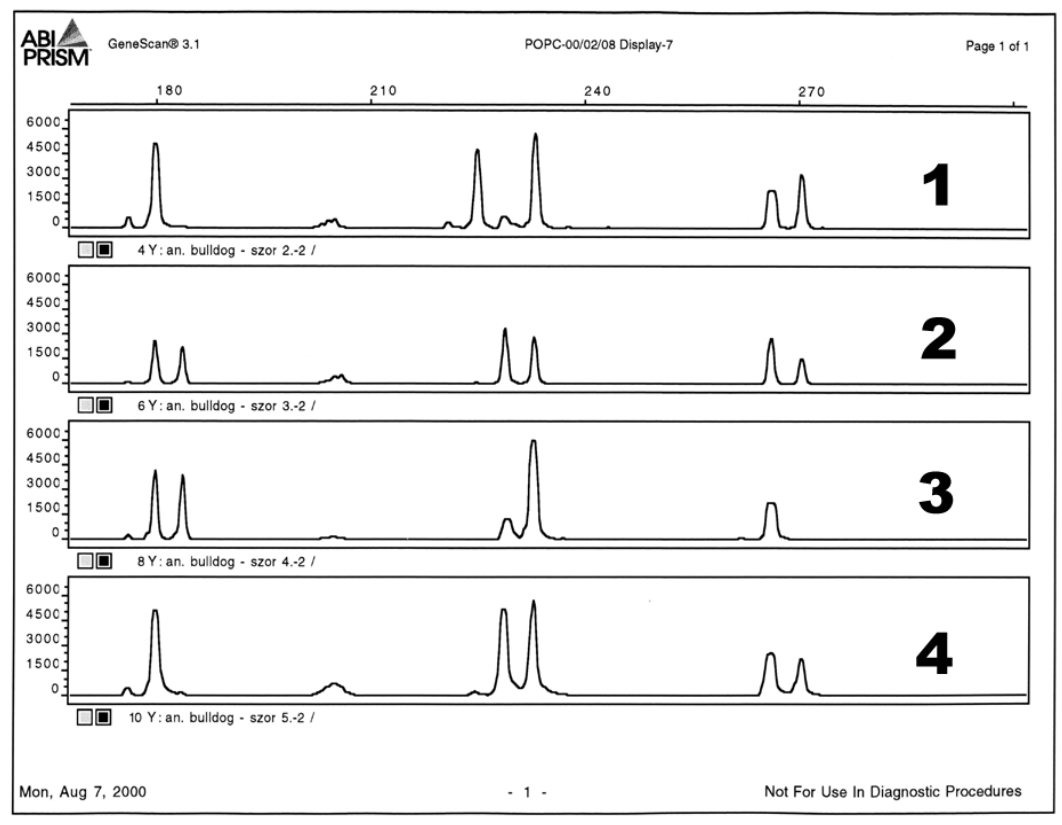

Fig. 2. Result of examination (left to right) of PEZ6, PEZ8 and FHC2079 loci $1=$ dam, $2=$ sire, $3=$ puppy $_{1}, 4=$ puppy $_{2}$ 


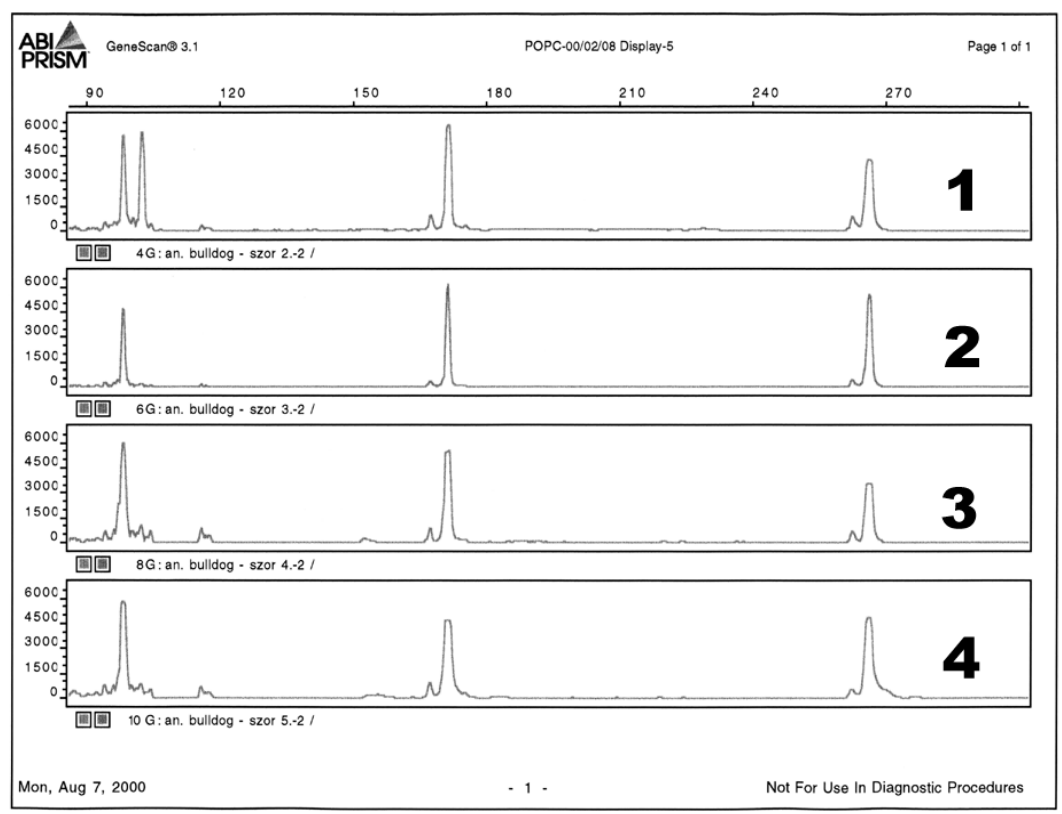

Fig. 3. High level of homozygosity at (left to right) PEZ5, PEZ20 and PEZ12 loci $1=$ dam, $2=$ sire, $3=$ puppy $_{1}, 4=$ puppy $_{2}$

\section{References}

FBI Laboratory (1994): PCR-Based Typing Protocols. FBI Laboratory, Washington, D.C.

Francisco, L. V., Langston, A. A., Mellersh, C. S., Neal, C. L. and Ostrander, E. A. (1996): A class of highly polymorphic tetranucleotide repeats for canine genetic mapping. Mammalian Genome 7, 359-362.

Fredholm, M. and Winters, A. K. (1996): Efficient resolution of parentage in dogs by amplification of microsatellites. Anim. Genet. 27, 19-23.

Shutler, G. G., Gagnon, P., Verret, G., Kalyn, H., Korkosh, S., Johnston, E. and Halverson, J. (1999): Removal of a PCR inhibitor and resolution of DNA STR types in mixed humancanine stains from a five year old case. J. Forensic Sci. 44, 623-626.

Vriesendorp, H. M., D-Duyzer-Den Hartog, B., Smid-Mercx, B. M. J. and Westbroek, D. L. (1974): Immunogenetic markers in canine paternity cases. J. Small Anim. Pract. 15, 693-699.

Zajc, I., Mellersh, C. S., Kelly, E. P. and Sampson, J. (1994): A new method of paternity testing for dogs, based on microsatellite sequences. Vet. Rec. 135, 545-547.

Zajc, I., Mellersh, C. S. and Sampson, J. (1997): Variability of canine microsatellites within and between different dog breeds. Mammalian Genome 8, 182-185. 